\title{
$A D$
}

AWARD NUMBER:

TITLE:

PRINCIPAL INVESTIGATOR:

RECIPIENT:

REPORT DATE:

TYPE OF REPORT:

PREPARED FOR:

DISTRIBUTION STATEMENT:
W81XWH-11-1-0657

Treatment-Based Classification versus Usual Care for Management of Low Back Pain

Dr. Daniel Rhon

The Geneva Foundation

Tacoma, WA 98402-4437

August 2015

Annual

U.S. Army Medical Research and Materiel Command Fort Detrick, Maryland 21702-5012

Distribution Statement A: Approved for public release; distribution is unlimited

The views, opinions and/or findings contained in this report are those of the author(s) and should not be construed as an official Department of the Army position, policy or decision unless so designated by other documentation. 


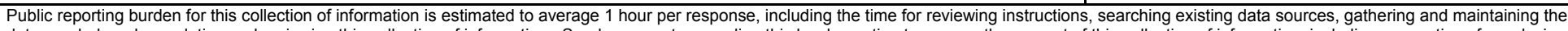

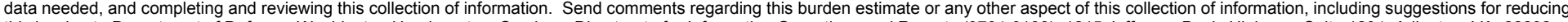

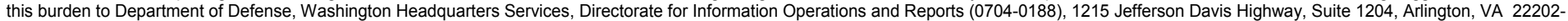

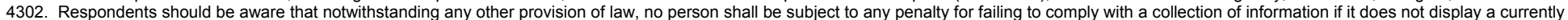
valid OMB control number. PLEASE DO NOT RETURN YOUR FORM TO THE ABOVE ADDRESS.

\begin{tabular}{l|l}
\hline 1. REPORT DATE & 2. REPORT TYPE \\
30 August 2015 & Annual
\end{tabular}

30 August 2015

4. TITLE AND SUBTITLE

Treatment-Based Classification versus Usual Care for Management of Low Back Pain

\section{DATES COVERED}

1Aug2014 - 31Jul2015

5a. CONTRACT NUMBER

5b. GRANT NUMBER

W81XWH-11-1-0657

5c. PROGRAM ELEMENT NUMBER

5d. PROJECT NUMBER

6. AUTHOR(S)

MAJ Daniel Rhon - dirhon@gmail.com 5e. TASK NUMBER

5f. WORK UNIT NUMBER

8. PERFORMING ORGANIZATION REPORT NUMBER

The Geneva Foundation

917 Pacific Avenue, Suite 600

Tacoma, WA 98402

U.S. Army Medical Research and Materiel Command

Fort Detrick, Maryland 21702-5012

11. SPONSOR/MONITOR'S REPORT NUMBER(S)

\section{DISTRIBUTION / AVAILABILITY STATEMENT}

Approved for Public Release; Distribution Unlimited

\section{SUPPLEMENTARY NOTES}

\section{ABSTRACT}

PURPOSE: The primary purpose of this study is to compare the effectiveness of two management strategies for patients with a recent onset of low back pain. One is based on usual care and the other is based on early access to physical therapy following a pragmatic treatment based classification approach. The secondary purposes are to compare the subsequent healthcare utilization associated with two management strategies as well as to evaluate the importance of psychosocial factors on outcomes within both groups of treatment.

DESIGN: A randomized trial comparing the effectiveness of two primary care management strategies for managing patients with a recent onset of low back pain (LBP). One strategy will be usual care (UC) based on a stepped care approach. The other strategy will involve early access to physical therapy (PT). The primary difference between the strategies is the management in the first 4 weeks.

SCOPE: Active duty Soldiers with low back pain - 1 year follow-up period MAJOR FINDINGS: No research findings to report at this time as we are still in the recruitment/enrollment process.

\section{SUBJECT TERMS}

Low back pain, military readiness, primary care, physical therapy

\begin{tabular}{|c|c|c|c|c|c|}
\hline \multicolumn{3}{|c|}{ 16. SECURITY CLASSIFICATION OF: } & \multirow{2}{*}{$\begin{array}{l}\text { 17. LIMITATION } \\
\text { OF ABSTRACT } \\
\text { UU }\end{array}$} & \multirow[t]{2}{*}{$\begin{array}{l}\text { 18. NUMBER } \\
\text { OF PAGES }\end{array}$} & $\begin{array}{l}\text { 19a. NAME OF RESPONSIBLE PERSON } \\
\text { USAMRMC }\end{array}$ \\
\hline $\begin{array}{l}\text { a. REPORT } \\
\text { Unclassified }\end{array}$ & $\begin{array}{l}\text { b. ABSTRACT } \\
\text { Unclassified }\end{array}$ & $\begin{array}{l}\text { c. THIS PAGE } \\
\text { Unclassified }\end{array}$ & & & $\begin{array}{l}\text { 19b. TELEPHONE NUMBER (include area } \\
\text { code) }\end{array}$ \\
\hline
\end{tabular}


1. Introduction 4

2. Keywords 4

3. Overall Project Summary 4

$\begin{array}{lll}\text { 4. Key Research Accomplishments } & 7\end{array}$

$\begin{array}{ll}\text { 5. Conclusion } & 7\end{array}$

$\begin{array}{lll}\text { 6. Publications, Abstracts, and Presentations } & 7\end{array}$

$\begin{array}{ll}\text { 7. Inventions, Patents and Licenses } & 7\end{array}$

$\begin{array}{lll}\text { 8. } & \text { Reportable Outcomes } & 7\end{array}$

$\begin{array}{ll}\text { 9. Other Achievements } & 7\end{array}$

$\begin{array}{ll}\text { 10. References } & 7\end{array}$

$\begin{array}{ll}\text { 11. Appendices N/A } & \text { NA }\end{array}$ 


\section{INTRODUCTION:}

Low back pain is the most significant contributor to lost workdays related to injury in the entire U.S. Armed Forces. The detrimental impact on combat readiness of low back pain cannot be understated, as back problems are the number one cause of evacuation from Iraq and Afghanistan, making it one of the largest causes of attrition in Soldiers in combat. This randomized clinical trial seeks additional evidence to determine if early physical therapy access using a treatment based classification (TBC) algorithm will result in greater improvements in function and quality of life and decreased healthcare utilization over 1 year as compared to a stepped "usual care" strategy in 120 active duty Soldiers presenting with low back pain.

KEYWORDS: low back pain, primary care, clinical guidelines, early intervention

\section{OVERALL PROJECT SUMMARY:}

In summary, recruitment for this trial has ended. There have many unforeseen challenges (outlined in detail below), but in all we have had a very resilient research team that has managed to work around the obstacles. We plan to finish up 1-year follow-ups by July 2016 and then analyze and report our findings.

SOW Tasks:

Initial Tasks (months 1-7): Coordinate IRB approval, investigator participation and subject recruitment in conjunction with ongoing standard of care for patients at MAMC healthcare clinics.

\begin{tabular}{|c|c|c|}
\hline $\begin{array}{l}\text { Task } \\
\#\end{array}$ & Task Title & Status \\
\hline a. & Submit study protocol to MAMC IRB (months 0-2) & $\begin{array}{l}\text { Submitted successfully June } \\
2011\end{array}$ \\
\hline b. & $\begin{array}{l}\text { Educate participating clinicians in the } 2 \text { treatment } \\
\text { algorithms (months 2-4) }\end{array}$ & $\begin{array}{l}\text { PTA research assistant has } \\
\text { been hired. She has completed } \\
\text { training. Have held } 2 \\
\text { meetings with staff at the } \\
\text { medical clinic where } \\
\text { enrollment will occur (once in } \\
\text { December 2011 and in } \\
\text { January 2012) }\end{array}$ \\
\hline c. & Receive approval for study by MAMC IRB (month 6) & Completed August 2011 \\
\hline d. & Receive approval for study by CIRO (months 6-11) & Completed November 2011 \\
\hline e. & $\begin{array}{l}\text { Establish administrative support for enrolling subjects } \\
\text { (months 5-8) }\end{array}$ & $\begin{array}{l}\text { Had a face to face meeting } \\
\text { with Dr. Fritz and Dr. Cleland } \\
\text { at a conference in November } \\
2011 \text { and also in February } \\
2012 \text {. We walked through the } \\
\text { entire methods. Subject } \\
\text { folders have been created for } \\
\text { data collection. }\end{array}$ \\
\hline f. & $\begin{array}{l}\text { Trial registered with clinicaltrials.gov (months 8-9) } \\
\text { http://clinicaltrials.gov/ct2/show/NCT01556581 }\end{array}$ & Trial registered in March 2012 \\
\hline
\end{tabular}

Aim 1: Compare the effectiveness of two primary care management strategies for patients with a recent onset of combat-related LBP. 
Task 1a (months 11-22): Enrollment into study (220 subjects). Active duty Soldiers with low back pain are randomized into one of two primary care management strategies (usual care stepped approach or early referral to physical therapy for treatment-based classification approach). Subjects are consented, baseline measures taken, randomization to treatment group occurs, and then allocated intervention is given.

\begin{tabular}{|l|l|l|}
\hline $\begin{array}{l}\text { Task } \\
\#\end{array}$ & Task Title & Status \\
\hline 1a & $\begin{array}{l}\text { Recruitment and enrollment of subjects began in } \\
\text { March 2012 }\end{array}$ & $\begin{array}{l}\text { We finished up enrollment at } \\
\text { the at all sites, with over 400 } \\
\text { subjects screened and 119 } \\
\text { enrolled. }\end{array}$ \\
\hline & Other notes: & $\begin{array}{l}\text { Met with Dr. Julie Fritz twice } \\
\text { during this year, once while } \\
\text { simultaneously attending a } \\
\text { conference, and also a site-visit } \\
\text { to UoU. }\end{array}$ \\
\hline
\end{tabular}

Task $1 \mathrm{~b}$ (months 12-34): Track outcomes at 4 weeks, 12 weeks, and 1 year after initial enrollment.

Method of tracking outcomes: Follow-up re-assessments will be performed 4 weeks, 12 weeks and 1-year after the baseline examination. Follow-up assessments will be performed by a Research Assistant blinded to the patient's treatment group assignment. Subjects will be called 2 weeks prior to their projected follow-up date and scheduled a follow-up appointment. Subjects will arrive at their appointment and fill out the appropriate outcome measures. The data from the outcomes will be placed in a patient folder with only their subject ID for identification. Data will then be entered into a protected spreadsheet as described in the protocol.

\begin{tabular}{|l|l|l|}
\hline $\begin{array}{l}\text { Task } \\
\#\end{array}$ & Task Title & Status \\
\hline $1 \mathrm{~b}$ & Follow-up of Subjects began & $\begin{array}{l}\text { We have had 80 subjects } \\
\text { complete the entire 1-year } \\
\text { period of the study. The rest } \\
\text { will complete within the next } \\
12 \text { months. }\end{array}$ \\
\hline
\end{tabular}

Aim 2: Compare the subsequent healthcare utilization associated with two management strategies for patients with a recent onset combat-related LBP.

The tasks (2) for Aim 2 cannot be started or completed until all the data collection from AIM $1 /$ Task 1 is completed.

Aim 3: Compare and contrast any differences in psychosocial factors between success and failures within both groups of treatment.

The tasks (3) for Aim 3 cannot be started or completed until all the data collection from AIM 1/ Task 1 is completed.

\section{Challenges:}

The task of recruitment of eligible subjects had become a challenge. Fort Lewis continues to be a prime location for access to active duty Soldiers. Our plan was detailed and the approach researched in detail, but there were 3 unanticipated events that have occurred affecting recruitment. 
1. We were unable to anticipate combat deployment schedules for the Soldiers as that information is classified and was not available at the time we formulated and submitted our grant proposal. At the start of the recruitment phase, two (2) of the three (3) Brigade Combat Teams (BCT) on Fort Lewis were deployed. This still allowed for recruitment to stay relatively on target as evidenced by our ability to screen 117 Soldiers, and recruit 26 subjects. Shortly following that, right at the beginning of the new fiscal year, all 3 BCT units were deployed and our eligible recruitment pool had significantly decreased. Two of those units began to return early 2013 and were finally processed back in and off of leave ready for regular garrison life by the beginning of May 2013. The other unit was in the same situation by the end of September 2013.

2. The sick call (walk-in) procedures that have been used for many years had recently changed between protocol derivation and implementation. Historically, patients have been able to come in for walk-in appointments in the morning. Traditionally, this is where we have been able to capture a high number of low back pain patients. Earlier this year, the Madigan Healthcare System rolled out an online and telephone appointment booking service, which gives Soldiers the option to call or schedule a same day appointment online. As we evaluated the use of this system we saw that more patients with LBP were opting to schedule an appointment later in the day rather than come in for the walk-in clinic in the morning. Even accounting for this, the overall numbers of patients seeking care for low back pain was unusually small.

3. The government sequestration had $2^{\text {nd }}$ and $3^{\text {rd }}$ order affects that impacted this study. The hospital leadership had put a lot of pressure on minimizing research and shifting priorities and resources to clinical care. The hospital had initially allotted the use of an additional civilian physical therapist for part-time help with this study. She was used often when MAJ Rhon had to travel for TDY or other mission-related travel. We lost the ability to use her. MAJ Rhon has some unanticipated travel for military required schooling and some unanticipated health issues. Usually these sorts of situations are covered by support from the hospital clinic, but in these cases we had no one to recruit/enroll during these periods of time. Future studies should consider funds to hire a full-time physical therapist at each site to counter the staff's FTE requirements for patient care.

4. Finally, MAJ Rhon has now completed a PCS move to San Antonio, and so recruitment can no longer occur at the Fort Lewis Site.

Plan: Systems went into place during active recruitment at Fort Lewis to help mitigate the issues stated above. These helped the research team reach an enrollment point of 80 subjects. Since then, we have added 2 other sites to the project with a target of enrolling 30-50 subjects at each of those additional sites.

\section{Career Development/Mentorship-Related Activities:}

- MAJ Rhon is now an active peer reviewer for the Journal of Orthopaedic and Sports Physical Therapy and Manual Therapy.

- MAJ Rhon and Dr. Fritz have been working 2 additional projects related to LBP, adding to the value of the mentoring relationship. He has had abstracts from that project accepted at 2 conferences and is working on a manuscript to summarize those findings.

- MAJ Rhon was able to use what he learned from mentoring and this current experience to lead the efforts as the PI for submission of a pre-proposal for another study through the PRORP

- MAJ Rhon had 1 manuscript published in this last year, in Clinical Orthopaedics \& Related Research

- MAJ Rhon applied for and was awarded another grant to study musculokeletal and thoracic spine injury prediction models in active duty service members, for $\$ 1.2$ million (Appendix E). Injury Prevention, Physiological and Environmental Health Award (IPPEHA)

Funding Opportunity Number: W81XWH-13-MOMJPC5-IPPEHA

- MAJ Rhon prepared, submitted, and had 2 new studies approved by the IRB related to low back pain

o Using Technology at the Point of Care to Influence Treatment Decisions Related to LBP Management 
o The effect of a pain medication educational approach before lumbar surgery on 6-month Postoperative use of opioid pain medication.

\section{KEY RESEARCH ACCOMPLISHMENTS:}

\section{Research:}

- IRB Approval by CIRO and MRMC

- Trial registered with ClinicalTrials.gov

- Enrollment and 1-year follow-up of subjects at the Fort Lewis completed

- Enrollment completed at Fort Bliss, waiting to complete 1-year follow-ups.

\section{REPORTABLE OUTCOMES:}

No presentations have yet been generated from data collected in this study as we are still in the data collection phase. Because the purpose of this initiative is dual in nature as a career development award, to both execute a relevant research trial and to focus on development of an independent clinician-scientist researcher, we have reported progress for both sections of this grant.

CONCLUSION: There are no significant outcomes to report as the trial is still following the final subjects through the end of 1 year.

REFERENCES: None 